\title{
INCLUSÃO DE PESSOAS COM DEFICIÊNCIA MENTAL NO TRABALHO
}

Eduardo José MANZINI ${ }^{1}$

GOYOS, Celso; ARAÚJO, Eliane. Inclusão social: formação do deficiente mental para o trabalho. São Carlos: Rima editora, 2006. 180p.

O livro Inclusão social: formação do deficiente mental para o trabalho vem ocupar um importante espaço sobre o tema deficiência e trabalho. Os pesquisadores e docentes que lidam com esse tema muito bem conhecem a dificuldade de encontrar material bibliográfico para subsidiar aulas, reflexões e pesquisas sobre a inserção da pessoa com deficiência no mercado de trabalho. Dessa forma o livro é muito bem vindo!

Sabemos que, atualmente, a organização do trabalho sofre grandes mudanças devido aos processos de informatização, globalização e especialização da mão-de-obra. Como, então, podemos vislumbrar a inserção da pessoa com deficiência mental para o trabalho?

Nesse sentido, o livro, organizado por Goyos e Araújo (2006), passa a ser fonte de informação para refletir sobre o tema.

O livro, composto por sete capítulos, apresenta conceitos básicos e fundamentais para entender e compreender a pessoa com deficiência mental e suas relações com o trabalho.

O leitor poderá encontrar importante reconstituição histórica sobre os primórdios da relação entre pesquisa e deficiência mental no Brasil, a legislação vigente e um levantamento teórico relevante de autores que trabalham com deficiência mental, ensino e currículo funcional. Esses conteúdos são apresentados de forma sistematizada e didática, e, principalmente, relacionados ao tema trabalho. Ao final de cada capítulo, os autores sugerem questões de estudo, com perguntas abertas, para promover a discussão sobre os conteúdos apresentados. Esse formato do livro evidencia a preocupação com a formação dos educadores, gestores e demais profissionais que trabalham ou irão trabalhar com o tema em pauta.

O livro abrange vários subtemas como:

1) aspectos sociais e legais relativos à deficiência mental;

\footnotetext{
${ }^{1}$ Departamento de Educação Especial da Faculdade de Filosofia e Ciências da Unesp campus de Marília manzini@marilia.unesp.br
} 
2) os processos básicos de aprendizagem que podem ser aplicados à deficiência mental;

3) o conceito de desenvolvimento humano;

4) os sistemas de avaliação e suas relações com o trabalho;

5) o planejamento para o ensino de pessoas com deficiência mental; e

6) o planejamento e organização de serviços para a formação de pessoas com deficiência mental para o trabalho.

Esse último tópico traz contribuições para as pessoas interessadas na organização de serviços para formação da pessoa com deficiência mental.

Sem dúvida, se vislumbrarmos que a formação para o trabalho da pessoa com deficiência mental é um dos últimos degraus para que a inclusão e os processos de autonomia ocorram, o livro será importante fonte de referência para ser utilizado na formação de alunos em cursos de pedagogia, psicologia, serviço social, terapia ocupacional, administração e outras áreas afins. 